\title{
AMIS Y AMILES: LA DIFUSIÓN DE UN TEMA MEDIEVAL EN ESPAÑA
}

\author{
CARLOS ALVAR ${ }^{1}$
}

Université de Genève

\section{Resumen}

Recorrido por las diferentes versiones latinas y francesas de la leyenda de Amís y Amile para detenerse posteriormente en las obras derivadas de esta leyenda en la literatura española: entre las versiones catalanas, se encuentra el Recull de exemples y miracles per alfabeto, el Llibre de les nobleses dels reys y la Història d'Amic i Melis, y entre las castellanas, destaca la Historia de Amic y Meliz y el Oliveros de Castilla y Artús d'Algarbe, además del capítulo 21 de los Siete sabios de Roma. Considera por último la conexión con esta leyenda del romance de Melisenda o Melusina y otros romances y obras dramaticas.

Palabras clave : Amís y Amile, leyenda, derivaciones, versiones catalanas, versiones castellanas, romancero, Historia septem sapientium, Scala coeli, Recull de exemples y miracles per alfabeto, Llibre de les nobleses dels reys y la Història d'Amic i Melis, Historia de Amic y Meliz, el Oliveros de Castilla y Artús d'Algarbe, Siete sabios de Roma.

\begin{abstract}
An overview of the different Latin and French version of the legend of Amis and Amile which previously would stop in the derivative legend in Spanish literature: between the Catalan versions what is found in Recull of examples and miracles per alphabet, the Book of the nobility of the monarchy and the History of Amic and Meliz and between Castilian emphasis on the History of the Amic and Meliz, Oliveros de Castilla and Artas D'Algarve. Additionally, there is chapter 21 of the Seven Sages of Rome. Lastly, is the last connection with this legend of the romance of Melisande or Melusina and other novels and plays.

Key words: Amis and Amile, legend, derivative, Catalan versions, Castilian versions, romancero, Historia septem sapientium, Scala coeli, Recull de exemples y miracles per alfabeto, Llibre de les nobleses dels reys y la Història d'Amic i Melis, Historia de Amic y Meliz, el Oliveros de Castilla y Artús d'Algarbe, Siete sabios de Roma.
\end{abstract}

1 Université de Genève. Correo-e: carlos.alvar@telefonica.net. Recibido: 28-02-2010; segunda versión: 0903-2010. 


\section{PREÁMBULO}

La primera versión conocida de la leyenda de Amís y Amiles se remonta al final del siglo XI y se halla en una epístola en dísticos latinos escrita por Radulfus Tortarius $^{2}$. Algo posterior es una versión hagiográfica, escrita al norte de Italia, bajo el título Vita sanctorum Amici et Amelii carissimorum, en la que los dos amigos forman parte del ejército de Carlomagno y mueren en Italia luchando contra Desiderio, el Lombardo; fueron enterrados en Mortara, donde eran venerados sus sepulcros. Enlaza este testimonio con los de algunos cantares de gesta, como el de la Chevalerie Ogier, en el que Ogier mata a Amís y Amiles, para causar un gran dolor a Carlomagno. Estos y otros hechos hicieron pensar a Bédier que la leyenda de Amís y Amiles se formó, posiblemente, en el monasterio de San Albino de Mortara y que, de allí, se extendió hacia Francia en boca de juglares y peregrinos (Bédier, 1907 : 161-183 y 337-360 y 1926, II : 178-206 ; Kölbing, 1884: XCVII-CX).

A partir del siglo XII es cuando esta leyenda tuvo mayor difusión por Europa. Aparece en un cantar de gesta francés y en un poema anglo-normando; en el siglo XIII en una versión latina en prosa y en el siglo XIV en la Historia de septem sapientibus en un manuscrito del año 1342 (Leach, 1937: ix-xiv). Y pocos años más tarde, la gesta inspiró una representación teatral en versos octosílabos franceses: el Milagro de Nuestra Señora con Amís y Amiles. La pieza se halla en una colección de obras teatrales que conservan dos manuscritos de la Biblioteca Nacional de Francia (mss. fr. Cangé 819 y 820) con un total de cuarenta piezas representadas entre los años 1339 y 1382 en el puy des orfevres à Paris $^{3}$. Durante este período la cofradía Saint-Eloi tenía por costumbre ofrecer a sus miembros la representación de un milagro como cierre de su reunión anual que se llevaba a cabo el 1 de diciembre. Este milagro de Amís y Amiles es el número veintitrés del primer volumen, siendo posiblemente representado en el año 1365. Luego vendrán las versiones en prosa del siglo XV (Woledge, 1939 : 433-456 y Martin, 2007 : 223-232).

Y así, en el transcurso de un par de siglos se encuentran versiones en latín y en fancés, en prosa y en versos pareados, en alejandrinos, en dodecasílabos, en decasílabos o en octosílabos... En cuanto al género, la amistad de los dos protagonistas ha pasado de ser una leyenda hagiográfica, a convertirse en un cantar de gesta, un exemplum o una obra teatral (Ribard, 1990 : 155-169). La difusión del tema por todo el Occidente europeo no hará sino añadir nuevos elementos, simplificar la trama, cambiar los nombre de los personajes, o el ámbito de la acción y el propósito general, dificultando el trabajo a los estudiosos.

La enorme versatilidad del tema, o si preferimos, su carácter proteico, se debe, posiblemente a los orígenes de la misma. Dejando al margen las hipótesis de quienes piensan en un origen griego (Asher, 1952) o en el culto a Cástor y Pólux como primera fuente de la leyenda (Krappe, 1932: 152-161), o a quienes creen que se trata de la amistad

2 Cf. Bar (1937 y 1982: 973-986). El texto latino se encuentra en la ed. de Hofmann (1882 : xx-xxxii).

3 Esta colección de piezas fue editada por G. París y U. Robert (1879). Pueden consultarse los siguientes estudios: Penn (1933), Glutz (1954), Runnalis (1968-1969: 15-22), (1970: 19-29) y (1970: 257-287) y Henrard-Warnier (1990: 463-477). 
de dos personajes históricos, Guillermo V de Aquitania y Guillermo IV de Angoulême ${ }^{4}$, es muy posible que la inmensa aceptación del relato y sus abundantes metamorfosis sean consecuencia de las naturales transformaciones de los géneros literarios con el transcurso del tiempo, favorecidas por la unión de dos temas folclóricos, conocidos bajos los nombres de «los dos hermanos» $\mathrm{y}$ «el servidor fiel»: el primero proporcionó la idea del tema, mientras que el segundo, el episodio de mayor fuerza dramática, como ya señaló G. Huet ${ }^{5}$.

\section{LA TRADICIÓN DIDÁCTICA: LOS EXEMPLA}

Estas importantes transformaciones no son suficientes para explicar la gran difusión de la leyenda. Al conjunto de circunstancias que propiciaron la expansión hay que añadir la presencia del relato en textos de carácter sapiencial, didáctico y moralizante: ése es el caso de la Historia septem sapientium, procedente del Libro de Sindibād, y de la Scala coeli, de Juan Gobi.

El Libro de Sindibād es una colección de cuentos que se difundió en dos versiones, una rama oriental (en la que se comprenden versiones en siríaco, griego, castellano, árabe, hebreo y tres en lengua pahlevi) ${ }^{6} \mathrm{y}$ una rama occidental que se desprendió de la versión hebrea (Mischle Sendabar) y dio origen al ciclo de los «Siete sabios de Roma». Esta traducción del hebreo al latín posiblemente se hizo en el siglo XII, pero se ha perdido. Nos quedan, sin embargo, versiones posteriores: una del siglo XIV titulada Historia de septem sapientium y la otra Dolopathos, de Juan de Alta Silva ${ }^{7}$. Pronto estas colecciones tuvieron gran difusión dando lugar a copias que variaban el número de relatos o el corpus de los mismos.

Dentro de la extensa tradición de esta obra, hay un manuscrito (Innsbruck, Cod. Lat. 310) del año $1342^{8}$, que agrega una versión de la leyenda de Amís y Amiles mezclada con el cuento de «El niño que comprendía el lenguaje de los pájaros» (Vaticinium) ${ }^{9}$. El relato está muy bien construido, pues el cuento sirve de marco dentro del cual se inserta la leyenda de Amís y Amiles. El niño que es arrojado por su padre al mar será después Alejandro (Amiles). Y toda la leyenda sirve para que se cumpla el vaticinio de que el niño se convertirá en rey. El relato en el momento de la anagnórisis de los personajes muestra un concepto providencialista de la historia: «Amigos, debéis saber que yo soy vuestro hijo a quien arrojasteis al mar. Dios por su gracia me salvó

\footnotetext{
4 Esta postura es defendida, entre otros, por Koch (1875), y más recientemente por Rasmussen, (1969).

5 Huet (1919: 162-186). La difusión de estos relatos en el folklore internacional fue inmensa al punto de ser recogidos en la colección de los hermanos Grimm (1995), Nos. 60 ("los dos hermanos") y 6 ("el servidor fiel").

6 La versión castellana fue editada por Lacarra (1989). Edición facsímil en Códice de Puñonrostro. El Conde Lucanor y otros textos medievales (1992). Vid. Alvar y Lucía Megías (2002: 948-950).

7 Vid. Perry (1959-1960: 1-94) y Kantor (1988). Ambos textos publicados por Hilka (1912 y 1913). Véase también la edición de Foehr-Janssens y Métry (2000).

8 Edición de Buchner (1889).

9 Vid. Polo de Beaulieu (1989 : 107-112).
} 
y me trajo a este estado» (p. 109). Al finalizar el relato con el vaticinio, el autor no puede hacer que sus héroes mueran y, por tanto, elimina el episodio de la lucha contra Desiderio y toda mención a la muerte de los protagonistas. En este sentido, es el único texto que no alude a Mortara ni a la muerte de los amigos.

Hay que recordar que el manuscrito de Innsbruck de la Historia septem sapientium deriva de la rama occidental del Libro de Sindibād, y que por lo tanto tiene una tradición textual distinta a la del Sendebar castellano: no extrañará que en el testimonio castellano, traducido del árabe, no aparezca ninguna referencia que haga pensar en la leyenda de Amís y Amiles.

El auge de la predicación que se produjo a lo largo del siglo XIII y el interés de los predicadores en reunir colecciones con exempla procedentes de los más variados orígenes hacen que reaparezca la leyenda de los dos amigos en la Scala coeli de Juan Gobi Junior (relato $\mathrm{n}^{\circ} 64$ ). Este predicador, muchas veces fue confundido con su tío, Juan Gobi Senior († 1328), prior del convento de Montpellier y de Saint-Maximin. Juan Gobi Junior no tuvo una carrera religiosa tan destacada como la de su tío. Nació en Alais, Provenza, en fecha desconocida. Se ordenó como dominico, fue prior del convento de su ciudad entre 1323 y 1324 y, a partir de 1327, prior del convento de Saint-Maximin. Ignoramos también la fecha de su muerte, aunque se piensa que debería situarse hacia 1350. Conservamos de él dos obras. Una, es un diálogo entre el autor y el fallecido Guy de Corbeau (†1323), titulado De spiritu Guidonis, questiones inter Johannem Gobi et spiritum Guidonis (de Corbo). Se trata de una discusión teológica sobre el Purgatorio y las indulgencias. La otra es la compilación de exempla titulada Scala coeli (entre 1323 y 1330). Contiene 972 relatos clasificados alfabéticamente por sus rúbricas - un tipo de ordenación textual que se había impuesto poco tiempo antes - que van de abstinentia a usura.

Gobi lleva a cabo aquí un importante trabajo de compilación de relatos, basándose en otras colecciones que estaban de moda en la época: las de Cesareo de Heisterbach, Étienne de Bourbon, Arnold de Liège, el Speculum exemplorum, etc. ${ }^{10}$. Concretamente, el relato 64, en el que se recoge la amistad de los dos nobles, se encuentra en otras colecciones, como el Alphabetum narrationum de Arnoldo de Lieja, de comienzos del siglo XIV, y el mucho más difundido Speculum Historiale de Vincent de Beauvais (h. $1250)^{11}$.

La colección reunida por Gobi es una muestra característica de lo que se denomina «instrumentos auxiliares de la predicación», es decir, textos que servían de apoyo para la preparación de los sermones. Esto determina la forma de su relato,

10 Datos referidos a este autor en Polo de Beaulieu (1991). Selección y traducción castellana de algunos relatos en Bizzarri (2007).

11 M.-A. Polo de Beaulieu (1991 : 639). En el manuscrito de Douai del Speculum historiale (ms. 797, del siglo XIV), el relato de las hazañas de Amicus et Amelius se encuentra en XXIV : 162-166 y 169. El Speculum historiale es la fuente de varios textos castellanos medievales, como una de las versiones de Barlaam y Josafat, la Disputa de Epicteto y Adriano y, tal vez, la Visión de don Túngalo. 
pues Gobi no busca el preciosismo literario, sino una finalidad práctica: su recreación atiende a la presentación de un esquema narrativo. Es por eso por lo que faltan muchos detalles en su relato y, por tanto, el lector para entender el exemplum en cuestión debe conocer necesariamente la leyenda. En estas colecciones los predicadores nos presentan bosquejos de los relatos que luego recrearían en los sermones. Allí era donde adquiría su plenitud el ejemplo religioso, pero esa «performance» era un segundo paso que hemos perdido debido a su carácter oral (Lecoy de La Marche, 1886 y Welter, 1927 [1973] : 304 y ss.).

Por otra parte, es evidente que la precedencia cronológica del Speculum historiale de Vincent de Beauvais, casi un siglo anterior a Gobi, le da una importancia muy especial al relato que contiene acerca de Amis y Amiles. La extraordinaria difusión del Speculum obliga a tenerlo bien presente cuando se habla de las versiones en lenguas vernáculas y también cuando se trata de las reelaboraciones en latín.

Como se ve, la leyenda ha ido emergiendo en las más diversas formas: relato epistolar, relato hagiográfico, cantar de gesta, representación teatral, exemplum... Y aún otras le esperaban en su derrotero por España.

\section{LA LEYENDA EN ESPAÑA: CATALUÑA}

Es difícil decir cuándo y cómo se introdujo esta leyenda en España. Dejando al margen la referencia contenida en el ensenhamen de Guerau de Cabrera, Cabra juglar, los testimonios más antiguos que se hallan en Cataluña y se sitúan a finales del siglo XIV: son el ejemplo núm. 48 del Recull de exemples y la narración contenida en el Llibre de les nobleses dels reys, ambos de carácter hagiográfico ${ }^{12}$. Hay, además, dos manuscritos del siglo XV (mss. 8 y 2546 de la Biblioteca de Catalunya) que reproducen de forma fragmentaria la versión "secular".

1. Recull de exemples y miracles per alfabeto (Biblioteca Universitaria de Barcelona, ms. 89). Copia de mediados del siglo XV. Contiene 712 ejemplos de diversa extensión y de orígenes muy variados, ordenados alfabéticamente, para facilitar el trabajo a los predicadores. Sigue muy de cerca el Alphabetum Narrationum de Arnoldo de Liège, tanto, que puede ser considerado una traducción del mismo (Welter, [1927] 1973 : 304 y ss.; Mussons, 1993 : 105-109 ; Sánchez Martí, 2000: 1603-1610). La historia de Amich y Meliç tiene pequeñas variantes con respecto a la contenida en el Alphabetum Narrationum, y como tal, formaría parte del discutido grupo de versiones hagiográficas, derivadas de la Vita Amici et Amelii carissimorum (Leach, 1937: IX-XVIII).

2. Llibre de les nobleses dels reys (Barcelona, Biblioteca de Catalunya, ms. 487). Copiado en la primera mitad del siglo XV. La obra está formada por 561 capítulos de carácter historiográfico, de procedencia muy variada (latina, francesa, provenzal y

12 El ensenhamen fue publicado por Riquer (1968: 342-351, y ahora 2009: 367 y ss.). 
catalana $)^{13}$. Aunque la obra comienza hablando de Amrot, rey de Troya, no tarda en cambiar de dirección, para centrarse en los reyes de Francia, desde el primero de todos, Moroynus. Este relato genealógico tiene intercalada la relación y los hechos de los reyes godos de España, sin omitir la invasión de los árabes, de acuerdo con un concepto historiográfico que recuerda la Estoria de España de Alfonso X o las Grandes Chroniques de France. El reinado de Carlomagno copia la versión catalana de la Crónica de pseudo-Turpín enriquecida con la Gesta Karoli Magni ad Carcassonam et Narbonam. A continuación, y a lo largo de los capítulos 81 a 88, se incluyen los hechos de Amic e Melis, situados en la época de Pipino: Amic era hijo del conde de Veryan, mientras que Melis lo era de un caballero de Bericha. El relato de las hazañas incluye el combate con el traidor, la enfermedad y la milagrosa curación gracias a la sangre de los dos niños; finalmente, se cuenta que ambos caballeros murieron combatiendo contra los lombardos. El relato recoge el enterramiento de Melis en la iglesia de San Pedro y de Amic en la de San Eusebio, y cómo el cuerpo de Melis apareció el día siguiente en la iglesia de San Eusebio, junto a su amigo.

Todo hace pensar que muy posiblemente el origen remoto del texto incluido en el Llibre de les nobleses dels reys es la Vita Sanctorum Amici et Amelii carissimorum, con la intermediación del Speculum historiale de Vincent de Beauvais, texto utilizado en esta parte por el autor de la compilación catalana, a juzgar por el planteamiento de conjunto y por los materiales historiográficos reunidos.

3. Història d'Amic i Melis (Barcelona, Biblioteca de Catalunya, ms. 8, conocido como Vega-Aguiló). De principios del siglo XV. El texto que nos interesa ocupa el último folio del códice (fol. 188v) y es un fragmento de apenas 37 líneas ${ }^{14}$. En él se narra cómo nacieron los dos niños en la ciudad de Germenia y fueron bautizados por un obispo, que los acogió hasta que entraron a servir al rey, desplazando en el afecto del monarca a otro noble, Cibrià, que por este motivo les guardará una profunda envidia...

4. Història d'Amich e Mèliç (Barcelona, Biblioteca de Catalunya, ms. 2546). Bifolio central de un cuaderno, escrito posiblemente hacia 1400. Este fragmento comienza con el encuentro amoroso de Mèliç y la hija del rey: “En pendre la filla del rey en sos braços leument e gitala en son lit". A continuación se narra el combate con el traidor, el episodio de la lepra de Amich y el sacrificio de los dos niños; el fragmento concluye con la recuperación del enfermo.

Ambos textos tienen variantes comunes: la acción comienza en una ciudad llamada Germenia; es el obispo quien los bautiza y no el papa; la hija del rey se llama

13 Descripción del ms. en Coll i Alentorn (1938 : 485-524 ); R. Aramón i Serra (1934). Mussons (1994: 725-735), especialmente p. 727 y ss.

14 Sánchez Martí (1999 : 373-383), donde publica el fragmento. Es posible que este folio sea del siglo XVI. 
Meliana y el traidor, Cibrià; la copa que sirve para el reconocimiento es de plata, etc. Estas variantes y otras de menor importancia hacen pensar que los dos testimonios fragmentarios derivan de una misma versión previa, hoy perdida, quizás llegada desde el Sur de Francia ${ }^{15}$. Algunos rasgos, como el papel activo de Meliana, la detallada descripción del combate, la voz reveladora o la asistencia al leproso por parte de un ayudante, serviría para situar a estos relatos en un grupo primitivo, en el que la leyenda estaría cerca del poema épico francés.

Los dos fragmentos son de mano distinta y formaban parte de volúmenes diferentes, de ahí que se pueda conjeturar que ambos testimonios siguen un mismo original perdido.

\section{LA LEYENDA EN ESPAÑA: CASTILLA}

Para Castilla las versiones e influencias son más tardías, pues se sitúan en el primer cuarto del siglo XVI, aunque es probable que la leyenda se conociera en tierras castellanas desde finales del siglo $\mathrm{XV}$, o quizás desde antes.

1. Historia de Amic y Meliz (Biblioteca privada de Alberto Sánchez Lerma). Fragmento de una hoja en $4^{\circ}$, impreso en los talleres sevillanos de los Cromberger entre 1528 y 1540, que se habían especializado en la publicación de obras de tema caballeresco dirigidas a un público poco exigente; este tipo de trabajos adquirieron con frecuencia la forma de pliegos sueltos: es posible que el relato de las hazañas de los dos amigos ocupara un total de ocho hojas en $4^{\circ}$, es decir, dos pliegos, a juzgar por el fragmento conservado. En la hoja que ha llegado hasta nosotros se cuenta la llegada de Amic, enfermo, al palacio de Meliz, donde será reconocido por la copa de plata, "la cual le avía dado el obispo cuando le baptizó". A continuación se narra la hospitalidad del amigo y cómo Amic oyó tres noches una voz que le decía cuál era el único remedio para su enfermedad. El texto se interrumpe en el momento en que Meliz se dispone a degollar a sus dos hijos ${ }^{16}$.

A pesar de la brevedad del fragmento, hay suficientes detalles para establecer una filiación: la copa de plata y no de oro, el obispo que bautizó a los dos amigos, la voz que anuncia el remedio para la enfermedad de Amic, la ausencia de elementos religiosos (el arcángel, por ejemplo), el nombre de "Meliana" que recibe la esposa de Meliz... Todo ello nos lleva a la misma tradición a la que pertenecen los fragmentos 8 y 2546 de la Biblioteca de Catalunya (supra núms. 3 y 4). Muy posiblemente, el texto castellano traduce el mismo original perdido del que derivan los citados testimonios catalanes o, quizás, traduce una copia muy cercana a éstos: el estado fragmentario de los tres testimonios no permite conocer con mayor exactitud las relaciones existentes entre ellos.

15 Véanse los trabajos de Mussons (1994: 725-735) y Sánchez Martí (1999: 373-383).

16 Estudió este fragmento de forma muy detallada Herrán Alonso (2003: 549-563), de donde tomo la información que sigue. 
La fecha de edición viene dada porque el fragmento que nos ocupa es citado en el inventario que se hizo de las existencias que había en el almacén de la imprenta a la muerte de Juan Cromberger (1540): “258. Amic e meliz”. Dado que en el inventario anterior, de 1528, no se cita la obra, es lógico pensar que la edición fue publicada y parcialmente vendida entre 1528 y 1540. Sin embargo, hay noticias anteriores de un libro con el mismo título, recogidas en el inventario de los bienes de Aldonza de Santa Fe, viuda zaragozana muerta antes de 1514: "un libro d'enprenta llamado Ami y Meliz". Nada más se puede deducir de forma segura (Griffin, 1998 : 257-373, especialmente pp. 267 y 315-316).

2. Oliveros de Castilla y Artús d' Algarbe (Burgos, Fadrique Biel de Basilea, 1499) es un libro de caballerías castellano, traducción o adaptación de la Histoire d'Olivier de Castille et Artus d'Algarbe escrita en la corte de Borgoña por Philippe Camus entre 1430 y 1460, a instancias de Jean de Croÿ, I conde de Chimay (Doutrepont, [1906] 1977). El itinerario recorrido -con algún eslabón más- se indica en la introducción del texto castellano:

[...] fue fallada vna [ystoria] en las corónicas del reino de Inglaterra que se dize la Istoria de Oliveros de Castilla y de Artús d'Algarbe, su leal compañero y amigo [...] E fue la dicha istoria por excelencia levada en el reino de Francia y venida en poder del generoso y famoso cavallero don Johan de Ceroy, señor de Chunay; el qual, desseoso del bien común, la mandó bolver en común vulgar francés, porque las infinitas virtudes de los dichos dos cavalleros Oliueros de Castilla y Artús d'Algarbe fuessen a todos manifiestas y conocidas. Y las trasladó el honrrado varón Felipe Camus, licenciado en utroque (Baranda 1995: 181-182).

El relato de Philippe Camus estaba construido sobre tres temas: el de "los dos hermanos" (o de Amís y Amiles), el del "muerto agradecido" y el de la "madrastra seductora". Esos tres ejes se mantienen en el texto castellano, y aunque aquí sólo nos interesa el primero de ellos, el de los "dos amigos", conviene recordar que la "madrastra seductora" se encuentra también en la tradición de los Siete sabios de Roma, a la que tendré que aludir más adelante.

Ya apuntó M. Menéndez Pelayo las coincidencias existentes entre el cantar de gesta francés y un libro de caballerías castellano, Oliveros de Castilla y Artús d'Algarbe (Menéndez Pelayo, 1943: 243): en primer lugar, hay que señalar la semejanza física: «[...] el rey no se fartava de mirar al infante Artús, fijo de la reyna, porque parescía de todo en todo a su fijo Oliveros, tanto que muchos se maravillavan y lo miravan pensando que era Oliveros» ${ }^{17}$. Otro de los rasgos en que se parecen las dos obras que tratamos es en la curación de Artús, que está aquejado de una «mortal pestilencia»y desprendía tal hedor, que todos le abandonaron, excepto Oliveros «[...] que jamás día ni noche se apartava de su compañía» (cap. 65, Baranda, 1995: 292). Los dos amigos tienen un sueño: «Oliveros, si tu compañero tuviesse la sangre de dos niños inocentes,

17 La historia de los nobles caualleros Oliveros de Castilla y Artús d'Algarbe (Baranda (ed.), 1995: 187), correspondiente al capítulo 4. Lucía Megías (1998) realizó una guía de lectura de esta obra. Philippe Camus, Histoire d'Olivier de Castille et Artus d'Algarbe (Régnier-Bohler (ed.), 2000: 985-1087). 
macho e fembra, y la beviese sin saber lo que era cobraría la salud de su cuerpo y la fermosura de su cara y la vista de sus ojos. Y si esto no le das, nunca le verás sano» (cap. 66, Baranda, 1995: 294).

Igual que en el texto francés Amiles, Oliveros mantiene una dura lucha interior antes de decidir la muerte de sus hijos: «cerró la puerta por dentro. Y fue para la cama de los niños y alçó la ropa para cortarles las cabeças. Y el fijo, que era de edad de cinco años, despertó y riendo y tendiendo los braços para abraçarle, le llamó padre; mas la fija, que era de menos días, no despertó. E quando Oliveros oyó su fijo que le llamava padre, le saltaron las lágrimas de los ojos y le cayó la espada de la mano y del grande dolor que hovo por su misma crueldad, le fue forçado apartarse de la cama» (cap. 67, Baranda, 1995: 296); «E fue a gran priessa a la cama de los niños y sin mirarlos en la cara, tomó el fijo por los cabellos y le cortó la cabeça y luego después a la fija y rescibió la sangre en el bacín. Y después tomó los cuerpos y los tornó en la cama y los cobrió como estavan de primero y puso las cabeças en sus lugares sobre los cuellos. Y tomó el bacín y cerró la puerta de la cámara con llaue» (cap. 67, Baranda, 1995: 297).

A continuación, Oliveros vuelve con la sangre a la cámara donde yacía su amigo y le da de beber dos vasos de ella: «Y no la hovo tan presto bevido quando todos los gusanos se le cayeron de la cabeça, e de la cara y echó por la boca toda la podre y ponçoña que tenía en el cuerpo. Y Oliveros le lavó con ella la cara y la cabeça, y por la voluntad de Dios le cresció la carne que estava comida y cobró la vista de los ojos» (cap. 68, Baranda, 1995: 297).

Los dos compañeros, entristecidos por la muerte de los niños, van a verlos: «E Oliveros, sin le poder responder palabra, le tomó por la mano y le levó a la cámara adonde dexara los niños muertos. $Y$ entrados en ella, cerraron la puerta por dentro y fueron a la cama de los niños, los quales por la gracia de Dios estavan vivos y sanos retoçando el uno con el otro» (cap. 69, Baranda, 1995: 299).

A partir de este punto, las historias francesa y castellana divergen totalmente.

Oliveros de Castilla y Artús d' Algarbe es adaptación de la Histoire d'Olivier de Castille et Artus d'Algarbe, según hemos dicho (Frontón, 1989 : 63-76; Corfis, 1997). Esta obra tuvo un éxito importante, a juzgar por los cinco manuscritos conservados, la reelaboración que hizo David Aubert por encargo de Philippe le Bon, y por el hecho de que muy pronto llegara a la imprenta. En efecto, el impresor ginebrino Louis Garbin publicó seis ediciones de la obra de Camus entre 1492 y 1497; a partir de la segunda edición (1493), el libro se vio enriquecido con una serie de grabados de extraordinaria calidad: doce de esas xilografías fueron reutilizadas por el mismo impresor en su edición de los Sept sages de Rome (1492) (Lokkös, 1978); resultaban así más patentes los lazos de unión entre la novelita de Camus y la colección de cuentos derivada del Libro de Sindibād. Luego vendrán las traducciones al castellano (1499), al flamenco (hacia 1510), al inglés (1518), al alemán (1521) y al italiano (a partir del castellano, 1552). En España hubo más de 52 ediciones del libro de caballerías entre finales del siglo XV y finales del siglo XIX, claro testimonio del éxito editorial alcanzado por la obra (Frontón, 1989 : 37-51; Vizcaíno, 2008 : 149-175). 
Sin duda, una parte importante de la fama lograda se debió a la presencia de dos caballeros homónimos a los conocidos héroes de la épica y de la novela: Olivier y Artus; pero también debió influir el cambio en la localización de los hechos, que ahora era la Península Ibérica, al menos en parte, territorio que estaba de actualidad gracias al matrimonio de Philippe le Bon con Isabel de Portugal (1430) (Régnier-Bohler, 1991 : 91 105). El tema de "los dos hermanos" había sido manejado con habilidad y oportunidad por Philippe Camus, y esa perspicacia dio sus frutos.

Por otra parte, Camus contextualizó el tema integrándolo en el de "la madrastra seductora", bien conocido gracias a las versiones de la Historia septem sapientibus. En una de las familias de testimonios de la rama occidental, familia $\mathrm{H}$, se recoge el tema de "los dos hermanos", que ahora se llaman Luis y Alexandre. En la biblioteca de Philippe le Bon había varios ejemplares de los Sept sages de Rome, según se indica en los inventarios de 1420 y de 1467 (Doutrepont, [1906] 1977: items 158-214).

La traducción castellana deriva de la segunda edición de Ginebra (1492) y se inscribe en el marco de las relaciones hispano-borgoñonas de finales del siglo XV, debidas a la política exterior de los Reyes Católicos (Cacho Blecua, 2002 : 349-370). Felipe el Hermoso, archiduque de Austria y duque de Borgoña, heredero del emperador Maximiliano I, casó con la infanta D $\mathrm{D}^{\mathrm{a}}$ Juana de Castilla, y en 1498 nombró caballero de honor de su esposa a Charles de Croÿ, nieto de Jean de Croÿ, I conde de Chimay, que entre 1430 y 1460 había encargado a Philippe Camus la Histoire d'Olivier de Castille et Artus d'Algarbe. La oportunidad política de la traducción y la necesidad de una leve readaptación resultaban claras, pero no era necesario alterar los planteamientos, ni modificar el tema de "los dos hermanos".

\section{Siete sabios de Roma}

El capítulo XXI de la traducción castellana de la Historia septem sapientibus tiene por título "Enxemplo que contó el hijo del emperador en que da a entender la firme fe y amistad que ha de tener un buen amigo a otro". Fue publicada en Burgos por Juan de la Junta en 1530. Se trata de la traducción de un texto en prosa latina perteneciente a la familia H de la citada colección de cuentos (Runte, Wikeley y Farrell, 1984).

Es una característica común a la familia $H$ fundir en un cuento los relatos referidos al tema de "los dos hermanos" y al del "Vaticinium", basado en la interpretación del lenguaje de los pájaros. Así ocurre en el manuscrito de Innsbruck (Cod. 310) al que hemos aludido más arriba ${ }^{18}$. Esta fusión de temas debió de producirse en la primera mitad del siglo XIV, pues hacia 1320-1330 se documentan los primeros testimonios en los que se da el cruce: se trata de algunas variantes de la Gesta Romanorum, obra posterior a la Scala coeli de Gobi y posterior a la primera Historia septem sapientibus que fundía los dos temas citados (Torre Rodríguez, 1992 : 103-115 y 1994 : 5-22).

Los dos amigos se llaman ahora Luis y Alexandre y son hijos del rey de Francia y del rey de Egipto respectivamente. La hija del emperador es Florentina...

18 Sobre las primitivas impresiones de esta obra vid. el estudio de Farrell (1980 : 57-66). Edición de González Palencia (1946: 117-276) y de Torre Rodríguez (1993). 


\section{Versiones posteriores}

Ya a finales del siglo XVI Pedro Hurtado de la Vera realizó la versión al castellano del Erasto italiano (Historia lastimera del Príncipe Erasto, hijo del Emperador Diocleciano. Amberes, Daniel Vervliet, 1573), reintroduciendo de este modo el cuento ya conocido de la Historia de septem sapientibus (Farrell 1980 : 57-66 ; González Palencia, 1946; Niedzielski, Runte y Hendrickson (eds.), 1978; Torre Rodríguez, 1990 y 1992 : 103-115).

Como es lógico, en época posterior los ecos que pueden durar de la leyenda son escasos y heterogéneos, lo que muestra que no hubo una tradición directa ni del poema francés ni de las versiones latinas. Así, por ejemplo, la Patraña trecena de Timoneda, en un relato alejadísimo de la gesta antigua, encontramos algunos motivos que pueden emparentarse con ella: el amigo que entra en batalla por otro, la espada desenvainada entre la pareja y, tal vez, nada más ${ }^{19}$; mientras que en los Cantos e historias de Gonzalo Fernandez Trancoso (1624) se vuelven a encontrar ecos - con independencia de las relaciones con Timoneda, ya discutidas por Menéndez Pelayo (1943: t. III, 137 y ss.). Pero tales ecos son tan remotos del Amís y Amiles como se puede comprobar ahora: los dos amigos tienen la misma edad, estudian juntos, tienen gran parecido, lo que les permite sustituirse en el tálamo nupcial, pobreza indigente de Cornelio y ayuda de Fabricio, su amigo... (Fernandez Trancoso, 1974: cuento IV).

Al tratar de El Rey don Pedro en Madrid o el Infanzón de Illescas, Menéndez Pelayo con su enorme capacidad de relacionar hechos dispersos, habló de la «extrañísima comedia» de Lope titulada Don Juan de Castro ${ }^{20}$. A don Marcelino le interesaban en ese momento las historias de apariciones y resucitados; no adujo algo que en esta ocasión parece muy pertinente. En las dos partes de la comedia (Menéndez Pelayo, 1949: 355) hay elementos que nos hacen pensar en el poema francés: dos niños nacidos al mismo tiempo y criados como hermanos, de gran parecido físico hasta el extremo que uno puede sustituir al otro, la castidad en el lecho (aunque falta el episodio de la espada) y alguna circunstancia más. Cierto que hay semejanza, pero pensaríamos en algo que pertenece a una tradición folklórica y no a imitación directa. Sin embargo, hay un episodio de rara similitud: Rugero contrae la lepra y don Juan - en sueños - oye voces que le indican cómo puede salvarse el amigo si bebe la sangre de sus dos hijos. Don Juan de Castro degüella a los hijos que yacen en la cama, bebe Rugero la sangre que le devuelve la salud y cuando van a comprobar el crimen, los dos niños juegan alegres en el lecho.

19 Vid. la edición de Ferreres (1980: 153-158). Lida de Malkiel (1976: 23) también adujo algunas reminiscencias en la Patraña IV.

20 Se pueden leer en el t. CCXLVI de la Biblioteca de Autores Españoles, pp. 81-202. Estudiando las relaciones piensa Lida de Malkiel (1976: 54) en algún original francés anterior a Oliveros de Castilla. 
En ocasiones se ha admitido la relación existente entre el cantar Amís y Amiles y otros textos castellanos, como el romance de la linda Melusina. «El nombre de Melusina o de Melisendra corresponde al de Belissent, hija de Carlomagno, en el poema de Amís y Amile», señalaba Menéndez Pelayo (Menéndez Pelayo, 1944: 279); deberían, pues, ponerse en contacto, más o menos remoto con este cantar todos los romances cuya protagonista se llama asíi ${ }^{11}$. De este grupo, el más cercano al Amís y Amiles sería el romance que comienza

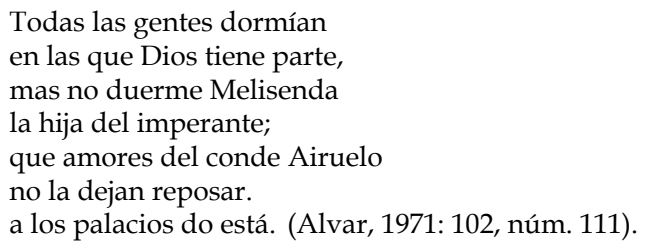

La princesa acude a la cama del conde Airuelo y ambos disfrutan del encuentro amoroso.

Se trata de un romance de típica inspiración francesa: escenas de cortesía y refinamiento, aparición de lo sobrenatural religioso, adivinación, especialmente por medio de un sueño présago y con primacía de tema amoroso más que de carácter militar o político como presentaba la antigua poesía castellana. Se puede admitir, a grandes rasgos, la relación temática del romance con uno de los episodios de la historia de Amís y Amiles; sin embargo, la semejanza no resiste un análisis mediatamente profundo. En sí no se debe pensar en una relación directa, sino, como bien señaló Samuel Armistead, en la existencia de «temas formulísticos» que se repiten en el campo épico y aún de una comunidad de repertorios temáticos entre la poesía épica francesa y la castellana ${ }^{22}$.

En otros romances se pueden hallar ecos del relato; así sucede, por ejemplo, en el Romance del Infante vengador, donde el infante reta a don Cuadros el traidor (sería el equivalente a Hardré en la chanson de geste), que ha dado muerte a seis hermanos del protagonista; a pesar de tener la razón de su parte, el retador no encuentre fiadores, salvo la hija del emperador; el triunfo del joven sobre su adversario, al que le corta la cabeza, supone el matrimonio con la bella doncella (Alvar, 1971: 81, núm. 91).

Más difícil aún resulta establecer la relación con otros romances, como los relativos a Gaiferos: este personaje marcha a la tierra donde está su tío; vive allí más de dos años; vuelve en figura de romero, para no ser reconocido, etc. (Alvar, 1971: 85 y ss., núms. 97 y 98); aunque estos pequeños detalles coinciden con el viaje de Amís a Roma, cuando está leproso, el tema no muestra ninguna semejanza con el del cantar de gesta.

También podrían relacionarse con el cantar francés los romances de Gerineldo: el paje es requerido de amores por Enilda, hija del rey; es ésta la mayor semejanza

21 Según Menéndez Pidal (1953, pp. 260-261) sobre este romance influyó la chanson de Aïol de donde proviene el nombre «Airuelo» y, sobre todo, la canción de Amis y Amiles de donde viene el nombre de Melisenda (Belisenda).

22 Véase el sugerente estudio de Armistead (1998: 55-68). 
que encontramos entre los dos textos. El tratamiento que el romance da al tema y el desenlace no se parecen en nada al cantar francés, ni a sus derivados ${ }^{23} \ldots$

Los cambios de nombre de los personajes principales y la adaptación de los hechos a nuevas circunstancias dejan de manifiesto una escasa identificación de la leyenda; por eso es dudoso que los romances citados deriven directa o indirectamente de la chanson de geste o de las reelaboraciones más tardías. Algunos temas, algunas escenas, algún motivo se dan con frecuencia en la tradición literaria medieval, en latín o en francés.

La espada en señal de castidad, por ejemplo, pertenece a la tradición germánica y no puede considerarse de inspiración directa. Aparece, por ejemplo, en el Don Tristán de Leonís castellano (Cuesta Torre, 1998: 36 y 1999: 138-140, cap. 65).

El nombre de Melisenda que aparece en algunos textos castellanos no es muestra de la proximidad de las tradiciones literarias, pues habría que señalar que Belisanda y Belisenda son los nombres de sendas princesas en dos libros de caballerías españoles: Belisanda es la hija del rey Recindos en Palmerín de Inglaterra (cap. LXXIV) ; Belisenda es la hija del rey Feremondo en el Don Tristán de Leonís (cap. V). Ambas obras tuvieron mayor difusión que la leyenda que nos ocupa. En concreto, el Tristán parece haber sido objeto de diez ediciones en el primer tercio del siglo XVI, por lo que habría llegado a un importante número de lectores, y ya había alcanzado difusión manuscrita con anterioridad (Cuesta Torre, 1997 : 227-236).

La visita de la princesa a la cama del héroe tampoco puede considerarse derivada del cantar, pues se halla en algunas versiones de la Demanda del Santo Graal: la hija del rey Bricos se enamora de Galaz y decide visitarle por la noche:

[...] pensó que aquella noche, quando los caualleros se echassen y que todos durmiessen, que se yría al lecho de Galaz, e assí lo fizo; quando vido que todos eran acostados, despojóse toda, saluo la camisa, e fuesse para allá muy vergonçosa e con gran pesar [...] se fue a do Galaz estaua $^{24}$.

Más precisa es la interpretación que aparece en el texto portugués de la misma obra:

A donzela, que bien cuidava que já dormiam e que sabia o leito de Galaaz, ela saíu de seu leito em camisa, empero mui vergonhosa e com gram pesar [...] E pero tornou em seu pensar, que the o amor conselhava, e esforçou-se tanto contra sua uontade, que foi a Galaaz e ergue o cubertor e deitou-se a-cabo dêle ${ }^{25}$.

\section{CONCLUSIÓN}

Son muy escasos los testimonios directos conservados de la presencia de la leyenda de Amís y Amiles en España: los testimonios más antiguos proceden de

23 La difusión de este romance llega hasta nuestros días. Vid. Catalán y Cid (1975).

24 Para todos estos personajes vid. Alvar (1991).

25 A demanda do Santo Graal, Magne (ed.), 1955: p. 147 a y b, vol. 1, cap. 113. 
Cataluña y derivan de la Vita, del Speculum historiale o de las colecciones de exempla reunidas por los predicadores a partir del siglo XIII, como el Alphabetum Narrationum.

En el dominio del castellano, la situación es más pobre todavía, pues los escasos testimonios se vinculan a los textos catalanes, quizás a través de un modelo común, o son versiones de textos franceses o latinos en los que la presencia de "los dos hermanos" constituyen un simple episodio, y no necesariamente el más significativo de los correspondientes relatos.

Reexaminados los testimonios anteriores al siglo XVIII, la presencia de la leyenda de los dos amigos en España apenas es una tenue línea continua en la que se reconoce la huella de la tradición hagiográfica y de la literatura culta:

1. La Vita sanctorum Amici et Amelii dio lugar al Llibre de les nobleses dels reys en catalán, quizás con el intermediario del Speculum historiale de Vincent de Beauvais.

2. El Alphabetum Narrationum de Arnold de Liège fue traducido en el Recull de exemples, también catalán.

3. Un original desconocido, quizás contemporáneo al canter de gesta francés, y de carácter secular está en la base de otro texto, también desconocido, que a su vez sirvió de modelo a la Història d'Amic i Melis y a la Història d'Amich e Mèliç catalanas y también a la Historia de Amic y Meliz castellana, si es que ésta no fue traducida del catalán.

4. La Histoire d'Olivier de Castille de Philippe Camus fue traducida en Oliveros de Castilla y Artús de Algarve.

5. Un ejemplar de la familia $\mathrm{H}$ de la Historia septem sapientibus, de principios del siglo XIV, dio lugar a los Siete sabios de Roma.

6. Los romances, y en especial los referidos al Conde Airuelo, podrían derivar de cualquiera de los testimonios citados.

Testimonios directos o presencia indirecta, la historia de los dos amigos, "los dos hermanos", perdurará en narradores posteriores como la española Cecilia Böhl de Faber, el chileno Ernesto Montenegro o en el cuento de El castillo de irás y no volverás. Es una pervivencia que pone de relieve la difusión de la literatura didáctica y moralizante, el éxito de las colecciones de ejemplos y cuentos reunidas por los predicadores, como los Siete sabios de Roma.

\section{BIBLIOGRAFÍA}

A demanda do Santo Graal I (1955): ed. A. Magne, Rio de Janeiro.

Alvar C. y J. M. Lucía Megías (2002): Diccionario Filológico de Literatura Medieval Española. Textos y transmisión, Madrid, Castalia: 948-950. 
Alvar, C. (1991): El rey Arturo y su mundo. Diccionario de mitología artúrica, Madrid, Alianza Tres.

Alvar, M. (1971): El romancero viejo y tradicional. México, Porrúa.

Aramón i Serra, R. (1934) : Novel.letes exemplars, Barcelona, Barcino.

Armistead, S. (1998): «Melisenda and the Chansons de geste», La Corónica, 27-1: 55-68.

Asher, J. A. (1952): Amis et Amiles. An Explanatory Survey, Auckland.

Bar, F. (1937) : Les epítres latines de Raoul le Tourtier (1065 ?-1114 ?). Étude et source. La légende d'Ami et Amile, Paris, Droz.

Bar, F. (1982): « Raoul le Tourtier et la chanson de geste d'Ami et Amile », en La chanson de geste et le mythe carolingien. Mélanges René Louis, Saint-Père-sous-Vézelay, Musée archéologique régional : 973-986.

Baranda, N. (ed.) (1995): Historias caballerescas del siglo XVI1, Madrid, Turner/Biblioteca Castro.

Bédier, J. (1907) : «Les chansons de geste et les routes d'Italie », Romania, 36 :161-183, 337-360 .

Bédier, J. (1926): Les légendes épiques. Recherche sur la formation des chansons de geste, 2, Paris, Champion: 178-206.

Bizzarri, H. O. (2007): Cuentos latinos de la Edad Media, Madrid, Gredos.

Buchner, G. (ed.) (1889): Die Historia septem sapientum, nach der Innsbrucker Handschrift v. J. 1342, nebst einer Untersuchung über die Quelle der Seuin Seages des Johne Rolland von Dalkeith, Erlangen \& Leipzig (Erlanger Beiträge, $\left.\mathrm{N}^{\circ} 5\right)$.

Cacho Blecua, J. M. (2002) : «De la Histoire d'Olivier de Castille al Oliveros de Castilla : Tradiciones y contextos históricos », Medioevo Romanzo, 27 : 349-370.

Camus, Ph. (2000): Histoire d'Olivier de Castille et Artus d'Algarbe, en D. Régnier-Bohler (ed.), Récits d'amour et de chevalerie. XIIe-XVe siècle, Paris, Robert Laffont: 9851087.

Catalán, D., y J. A. Cid (1975): Gerineldo, el paje y la infanta, Madrid, Gredos-Seminario Menéndez Pidal, 3 vol.

Códice de Puñonrostro. El Conde Lucanor y otros textos medievales (1992), Madrid, Real Academia Española.

Coll i Alentorn, M. (1938) : «El libre de les nobleses dels reys », Estudis Universitaris Catalans, 12 : 485-524.

Corfis, I. A. (1997) : La 'Historia delos nobles cavalleros Oliveros de Castilla y Artus d'Algarve'. From Romance to Chapbook: The Making of a Tradition. Madison, Hispanic Seminary of Medieval Studies.

Cuesta Torre, M. L. (ed.) (1999): Tristán de Leonís (Valladolid, Juan de Burgos, 1501), introducción y edición, Alcalá de Henares, Centro de Estudios Cervantinos ("Los libros de Rocinante"). 
Cuesta Torre, M. L. (1998): Tristán de Leonís (Valladolid, Juan de Burgos, 1501): Guía de lectura, Alcalá de Henares, Centro de Estudios Cervantinos (Guías de lectura caballeresca, 3).

Doutrepont, G. ([1909] 1970) : La littérature française à la cour des Ducs de Bourgogne, Genève, Slatkine Reprints.

Doutrepont, G. ([1906] 1977): Inventaire de la « librairie » de Philippe le Bon : 1420. Genève, Slatkine Reprints.

Farrell, A. J. (1980) : "Version H of the Seven Sages: A Descriptive Bibliography of Spanish Editions", La Corónica, 9 : 57-66.

Farrell, A. J. (1980): «Version H of The Saven Sages: A Descriptive Bibliography of Spanish Editions», La Corónica, 9-1 : 57-66.

Fernandez Trancoso, G. (1974): Contos e histórias de Proveito et Exemplo (Texto integral conforme a ediçao de Lisboa de 1624), texto preparado por J. Palma-Ferreira, Lisboa.

Ferreres, R. (ed.) (1980): El Patrañuelo, Madrid, Castalia.

Foehr-Janssens, Y. y E. Métry (eds.) (2000) : Jean de Haute-Seille. Dolopathos ou le roi et les sept sages, Turnhout (Bélgica), Brepols.

Frontón, M. A. (1989) : «Del Olivier de Castille al Oliveros de Castilla : Análisis de una adaptación caballeresca », Criticón, $46: 63-76$.

Frontón, M. A. (1989) : «La difusión del Oliveros de Castilla : Apuntes para la historia editorial de una historia caballeresca », Dicenda, $8: 37-51$.

Glutz, R. (1954): Miracles de Nostre Dame par personnages: Kritische Bibliographie und neue Studien zu Text, Entstehungszeit und Herkunft, Berlín.

González Palencia, A. (1946): Versiones castellanas del "Sendebar". Madrid-Granada, CSIC.

González Palencia, A. (ed.) (1946): Versiones castellanas del Sendebar, Madrid-Granada, CSIC: $117-276$

Griffin, C. (1998) : «El inventario del almacén de libros del impresor Juan Cromberger : Sevilla 1540 », en M.I. Hernández González (ed.) (1998): El libro antiguo español. IV. Coleccionismo y Bibliotecas (siglos XV-XVIII). Salamanca, Universidad : 257373.

Grimm (Hermanos) (1995), Kinder- und Hausmärchen, Stuttgart, Reclam.

Henrard-Warnier, N. (1990): «Amis et Amile: de la geste à la scène», Le Moyen Age, 96 $\mathrm{N}^{\circ} 4: 463-477$.

Herrán Alonso, E. (2003): «Amicus o la historia de la amistad verdadera. Otro testimonio peninsular», Hispanic Review, 71.4: 549-563.

Hilka, A. (1912): Historia de septem sapientum. I. Eine bisher unbekannte lateinische Übersetzung einer orientalischer Fassung der Sieben weisen Meister (Mischle Sendebar), Heidelberg, Carl Winter's Universitätbuchhandlung. 
Hilka, A. (1913): Historia septem sapientum. II. Johannis de Alta Silva Dolopathos siue De rege et septem sapientibus, nach den festländischen Handschriften kritisch herausgegeben, Heidelberg, Carl Winter's Universitätbuchhandlung.

Hofmann, K. (ed.) (1882) : , Amis et Amiles II, Auflage, Erlangen, Verlag von Andreas Deichert.

Huet, G. (1919) : " Ami et Amile : Les origines de la légende », Le Moyen Age, 2a série, $21: 162-186$.

Kantor, S. 1988: El Libro de Sindibād. Variaciones en torno al eje temático «engaño-error», Madrid, BRAE, (Anejo 42).

Koch, J. (1875): Über Jourdain de Blaivies, Königsberg.

Kölbing, E. (ed.) (1884) : Amis and Amiloun : Vita Amici et Amelii carissimorum, Heilbronn, Henninger.

Krappe, A. H. (1932): «The Legend of Amicus and Amelius», Modern Language Review, 18: 152-161.

La historia de los nobles caualleros Oliveros de Castilla y Artús d'Algarbe en N. Baranda (ed.) (1995): 181-313.

Lacarra, M J J. (ed.) (1989): Sendebar, Madrid, Cátedra.

Leach, M. (1937 [Reprint, 1960]): Amis and Amiloun, London, Early English Texts Society.

Leach, M. (1937) : Amis and Amiloun. London, Early English Text Society : IX-XVIII.

Lecoy de La Marche, M. (1886) : La chaire française au Moyen Âge, Paris.

Lida de Malkiel, Ma R. (1976): El cuento popular y otros ensayos, Buenos Aires, Losada.

Lokkös, A. (1978) : Catalogue des incunables imprimés à Genève 1478-1500, Genève, Bibliothèque de Genève.

Lucía Megías, J. M. (1998): Guía de lectura de Oliveros de Castilla, Alcalá de Henares, Centro de Estudios Cervantinos.

Martin, J.-P. «Les nouvelles aventures d' Ami et Amile au XVe siècle », in Ch. ConnochieBourgne (ed.) (2007), Façonner son personnage au Moyen Age, Aix-en-Provence, CUERMA, Université de Provence : 223-232.

Menéndez Pelayo, M. (1943): Orígenes de la novela I, Madrid, CSIC, en Edición nacional de las obras completas de Menéndez Pelayo XIII, edición preparada por E. Sánchez Reyes, Madrid, Consejo Superior de Investigaciones Científicas.

Menéndez Pelayo, M. (1944): Antología de poetas líricos VII, Madrid, CSIC.

Menéndez Pelayo, M. (1949): Estudios sobre el teatro de Lope de Vega IV, en Edición nacional de las obras completas de Menéndez Pelayo XXXII, Madrid, Consejo Superior de Investigaciones Científicas.

Menéndez Pelayo, M. (1943): Orígenes de la novela III, en Edición nacional de las obras completas de Menéndez Pelayo XV, edición preparada por E. Sánchez Reyes, Madrid, Consejo Superior de Investigaciones Científicas. 
Menéndez Pidal, R. (1953): Romancero hispánico (hispano-portugués, americano y sefardí. Teoría e historia I, Madrid, Espasa-Calpe.

Mussons, A. M (1993) «Estudio del Recull de exemples y miracles per alfabeto », Literatura Medieval. Actas do IV congresso da Associação Hispânica de Literatura Medieval II, Lisboa, Cosmos : 105-109.

Mussons, A. M (1994): «La istoria de Amiche Melis», Actas del III Congreso de la Asociación Hispánica de Literatura Medieval I , Salamanca: 725-735.

Niedzielski, H. , H. R. Runte y W. L. Hendrickson (eds.) (1978) : Studies on the Seven Sages of Rome and Other Essays in Medieval Literature Dedicated to the Memory of Jean Misrahi. Honolulu, Educational Research Associates.

París, G. y U. Robert (eds.) (1879), Miracles de Nostre Dame par personnages, París, Firmin Didot.

Penn, D. (1933): The Staging of the Miracles de Nostre Dame par personnages of the Ms Cangé, New York.

Perry, B. E. (1959-1960): «The Origin of the Book of Sindibad», Fabula, 3: 1-94 .

Polo de Beaulieu, M.-A. (1989) : "Le garçon qui comprend le language des oiseaux », in J. Berlioz, C. Brémond et C. Velay-Vallentin (eds.) (1989) : Formes médiévales du conte merveilleux, Paris, Stock : 107-112.

Polo de Beaulieu, M.-A. (ed.) (1991): La scala coeli de Jean Gobi, Paris, Édition du CNRS.

Rasmussen, B. H. (1969) : Le cycle de Blaye et l'histoire, Heidelberg, Studia Romanica.

Régnier-Bohler, D. (1991) : «L'avenèment de l'espace ibérique dans la littérature médiévale française », en A. A. Nascimento y C. A. Ribeiro (eds.), Actas do IV Congresso da Associação Hispânica de Literatura Medieval I, Lisboa, Cosmos : 91105.

Ribard, J. (1990) : "Ami et Amile, une 'oeuvre-carrefour' », en Actes du XIe Congrès International de la Société Rencesvals (Memorias de la Real Academia de Buenas Letras de Barcelona, 21 y 22), Barcelona : 155-169.

Riquer, M. de (1968): Les chansons de geste françaises, Paris, Nizet.

Riquer, M. de (2009) : Los cantares de gesta franceses, trad. M ${ }^{\text {a }}$ R. Bastardas, Madrid, Gredos.

Runnalis, Gr. (1968-1969): «The Manuscript of the Miracles de Nostre Dame par personanges», Romance Philology, 22: 15-22.

Runnalis, Gr. (1970): «Medieval Trade Guilds and The Miracles de N. D. par personnages», Medium Aevum, 39: 257-287

Runnalis, Gr. (1970): «The Miracles de N. D. par personnages: erasures in the Manuscrpt and the Dates of the Plays and the Serventois», Philological Quaterly, 49: 19-29.

Runte, H. R., J. K. Wikeley y A. Farrell (1984) : 'The Seven Sages of Rome' and the 'Book of Sindbad'. An Analytical Bibliography. New York-London, Garland. 
Sánchez Martí, J. (1999) : «La llegenda d'Amich i Mèliç : Una versió secular », Actes del VII Congrés de l'Associació Hispànica de Literatura Medieval III, Castelló de la Plana, Universitat Jaume I : pp. 373-383.

Sánchez Martí, J. (2000 ) : «La historia de Amicus y Amelius en Cataluña : El Eximpli e miracle dels dos leals amichs, Amich e Meliç », Actas del VIII Congreso Internacional de la Asociación Hispánica de Literatura Medieval II, Santander, Gobierno de Cantabria:1603-1610.

Torre Rodríguez, V. de la (1990) : Variantes occidentales castellanas del Sendebar. Ciclo de los Siete Sabios de Roma. Madrid, Univ. Complutense.

Torre Rodríguez, V. de la (1992) : «Filiación de las versiones castellanas del ciclo Siete sabios de Roma. Variantes del Sendebar occidental », Revista de Filología Española, 72 : 103-115.

Torre Rodríguez, V. de la (1994) : "Amicus et Amelius en el Libro de los Siete Sabios de Roma», Revista de Literatura, 56 : 5-22.

Torre Rodríguez, V. de la (ed.) (1993): Los siete sabios de Roma, Madrid, Miraguano Ediciones.

Vizcaíno, R. (2008) : "Ami et Amile e La historia delos nobles caualleros Oliueros de Castilla y Artus d'Algarve : Unha análise comparativa », Revista de Literatura Medieval, 20 : 149-175.

Welter, J.-Th. ([1927] 1973) : L'exemplum dans la littérature religiuse et didactique du Moyen Age, Genève, Slatkine Reprints.

Woledge, B. (1939) : «Ami et Amile. Les versions en prose française », Romania, 65 : 433-456. 